\title{
ANÁLISIS CARTOGRÁFICO DEL NIVEL DE AFECTACIÓN DE LOS INCENDIOS FORESTALES SOBRE ÁREAS URBANIZADAS EN LA COSTA DEL SOL OCCIDENTAL (1991-2013)
}

\author{
José Romero-Padilla ${ }^{1}$, Juan Francisco Martínez Murillo ${ }^{1}$ \\ Universidad de Málaga
}

\begin{abstract}
RESUMEN
La Costa del Sol occidental es uno de los espacios más complejos respecto a su ordenación territorial, especialmente, cuando se ve afectado por el peligro derivado de los incendios forestales que ocurren en áreas cercanas a los núcleos urbanos. Este trabajo analiza el grado de afección de los incendios forestales en estas áreas, ocurridos en los municipios de la Costa del Sol occidental (provincia de Málaga), durante el periodo 1991 a 2013. Tras realizar un análisis descriptivo del fenómeno de los incendios, se ha caracterizado el grado de afección a los núcleos poblacionales a partir de la cercanía a los mismos. Los resultados concluyen que el área de estudio es la más afectada del conjunto provincial malagueño. La cartografía muestra además que la población potencialmente afectada por el fuego tiene una variabilidad anual muy elevada, aunque cada vez es más frecuente que se vea afectada directa o indirectamente, haciendo necesario la actualización constante de los sistemas de protección a la población.
\end{abstract}

Palabras claves: incendios forestales; urbanización; Costa del Sol; Mediterráneo.

\section{CARTOGRAPHIC ANALYSIS OF THE LEVEL OF AFFECTATION OF FOREST FIRES ON URBANIZED AREAS ON THE WESTERN COSTA DEL SOL (1991-2013)}

\begin{abstract}
The Western Costa del Sol is one of the most complex spaces with respect to its territorial planning, especially when it is affected by the danger derived from forest fires that occur in areas close to urban centres. This work analyzes the degree of impact of forest fires in these areas, which occurred in the municipalities of the western Costa del Sol (province of Malaga), during the period 1991 to 2013. After conducting a descriptive analysis of the phenomenon of fires, It has characterized the degree of affection to the population centers from the proximity to them. The results conclude that the study area is the most affected of the province of Malaga. The cartography also shows that the population potentially affected by fire have a very high annual variability, although it is increasingly common to be affected directly or indirectly, making it necessary to constantly update the population protection systems.
\end{abstract}

Keywords: Wildfire; urbanization; Costa del Sol; Mediterranean.

\footnotetext{
${ }^{1}$ Universidad de Málaga. E-mails: romeropadilla12@gmail.com ; juanfmmurillo@gmail.com
} 


\section{INTRODUCCIÓN}

La Costa del Sol Occidental es un territorio conformado por una banda de $20 \mathrm{~km}$ de ancho y $80 \mathrm{~km}$ de longitud que se localiza en el sur de España, en la provincia de Málaga, entre África y Europa. Situada entre el mar Mediterráneo y un conjunto de cadenas montañosas de alto valor medioambiental, acogiendo a su traspaís próximo, queda protegida de los vientos fuertes, suavizando aún más su clima mediterráneo. El paisaje es complejo y muy variado, con un fuerte contraste entre la zona costera, las sierras y el interior. En el borde marítimo, las playas y desembocaduras fluviales han sido alteradas hasta su máxima artificialidad. En el interior, coexiste un fuerte contraste entre los espacios montañosos de vocación forestal y los espacios transformados por la expansión urbanística y turística ocurrida desde la costa hacia el interior. Tras cincuenta años de actividad turística, el paisaje de la Costa del Sol Occidental, se presenta profundamente marcado por la huella del ser humano, habiendo pasado a ser más un producto de una vida urbana refinada que una creación natural (GALACHO JIMÉNEZ \& LUQUE, 2000). El litoral malagueño, por su proximidad con el estrecho de Gibraltar (al paraíso fiscal, al puerto de Algeciras y al norte de África), y su consolidación como destino turístico internacional, se ha convertido en una de las zonas urbanas metropolitanas más dinámicas del mediterráneo español: está conectada globalmente y por ello, el territorio centroeuropeo forma parte de su socioecosistema urbano abierto (ROMERO MARTÍNEZ et al., 2015).

Este complejo espacio ha venido a convertirse en uno de los más complejos en cuanto a su ordenación y gestión territorial, especialmente, cuando se ve afectado por el riesgo derivado de los incendios forestales que ocurren en áreas cercanas a los núcleos urbanos. Esta zona comprende el terreno forestal en contacto con zonas edificadas (GALIANA, 2012), designándose así al escenario territorial de un nuevo fenómeno: el fuego urbano-forestal, un tipo de incendio que no sólo puede alcanzar, sino que además puede propagarse en el interior de los desarrollos edificatorios, lo que hace que surjan unos problemas específicos, sustancialmente distintos a los provocados por los incendios puramente forestales o urbanos (PYNE et al., 1996). Así pues, el territorio de interfaz es el susceptible de ser afectado por incendios forestales, pero al mismo tiempo constituye una fuente de peligro, pues se trata de un ámbito donde las probabilidades de ignición por causas humanas son mucho más frecuentes (VILAR DEL HOYO, 2008).

El paisaje de las áreas urbanizadas ha llegado a definir un verdadero paisaje de referencia en el monte mediterráneo en diferentes ámbitos del territorio español (GALIANA, 2012). Según el mapa de vegetación forestal y áreas urbanizadas elaborado por Montiel y Herrero (2000), la Costa del Sol occidental aparece como una de las zonas con mayor intensidad de uso urbano y turístico en contacto con zonas forestales, junto a otras españolas de similares características, como las comarcas de la Marina en Alicante y el Ampurdán en Girona, además de las coronas metropolitanas de Barcelona, Madrid y Valencia (GALIANA MARTÍN, 2012).

La expansión de la urbanización a entornos forestales se está traduciendo en un incremento de los episodios de fuego urbano-forestal en España, como por ejemplo los que acompañaron a las grandes oleadas de incendios que afectaron a Canarias (2007) o Galicia (2006), y que son cada vez más comunes en ámbitos fuertemente urbanizados como Madrid y Cataluña. Este incremento de la vulnerabilidad viene determinado por una evolución territorial en la que están presentes dos factores. Por un lado, una dinámica de progresión de la vegetación que se traduce en una mayor continuidad (tanto vertical como horizontal) de las formaciones forestales, lo que facilita la propagación de los incendios (BADÍA et al., 2002). Y, por otro, por una marcada tendencia a la dispersión de los procesos de urbanización, especialmente en ámbitos metropolitanos y litorales. De la interacción entre ambos factores se deriva una multiplicación de las áreas urbanizadas (GALIANA, 2012).

En la comunidad autónoma andaluza, el Plan de Emergencia por Incendios Forestales de Andalucía desarrollado por el INFOCA incluye la totalidad de la provincia malagueña en las zonas de peligro de incendio (Decreto 371/2010, de 14 de septiembre; modificado en 160/2016, de 4 de octubre), cuya función básica es "garantizar la protección del medio natural frente a estos siniestros, gracias a una extensa red de instalaciones, recursos terrestres y aéreos que se movilizan de forma automática cada vez que se produce algún incendio forestal" (Consejería de Agricultura, Ganadería, Pesca y Desarrollo Sostenible, Junta de Andalucía).

Debido al peligro que suponen los incendios en estos espacios urbano-forestales y el riesgo al que queda sometida su población, son frecuentes las investigaciones que tratan de analizar ese fenómeno. Lein y Stump (2009) modelizaron las variables de peligro y riesgo asociadas a los fuegos de estas áreas utilizando variables como el combustible acumulado, la radiación solar, la pendiente del terreno, para el primero, y la densidad de población y la distancia a la red viaria, para el segundo. Castillo Soto (2012) estudió los valores umbrales y de distancia a la que el efecto de la densidad de fuego (número de eventos por unidad de superficie), así como las áreas de influencia en un área de urbanización extensiva en Chile. Romero-Calcerrada et al. (2008)

Papeles de Geografía, 65 (2019), 49-66 
estudiaron los patrones espaciales de las causas de ignición de incendios en áreas urbanas en el suroeste de la Comunidad de Madrid.

La Costa del Sol occidental no es ajena a estos procesos espaciales ocurridos en España, especialmente, desde el cambio de paradigma socioeconómico acaecido durante la década de los años cincuenta del pasado siglo. Es especialmente evidente desde los años 90 del siglo XX a la primera mitad del siglo XXI, cuando la superficie urbanizada crece bastante, pudiendo quedar la población al albur de la ocurrencia de incendios forestales, generalmente originados por negligencias. Un claro ejemplo fue el incendio de Barranco Blanco ocurrido en esta comarca malagueña a finales de agosto de 2012, el de mayor extensión de los últimos 30 años, con más de 8.000 ha calcinadas, pero también uno de los que entrañó más peligro para la población residente en las áreas urbanas cercanas. Ambos hechos, la expansión urbanística y la irregularidad temporal de los incendios forestales, pero en general, justifica este trabajo, que tiene como objetivos: i) analizar la dinámica territorial de los incendios forestales en la Costa del Sol occidental durante el periodo 1991-2013; ii) caracterizar la evolución espacial de las áreas urbanizadas en el mismo periodo; y iii) analizar la cercanía de las áreas urbanizadas a los incendios forestales ocurridos.

\section{2. ÁREA DE ESTUDIO}

El área de estudio se corresponde con la comarca de la Costa del Sol occidental, situada en el suroeste de la provincia de Málaga (Figura 1). La comarca se encuentra integrada por los siguientes municipios, de este a oeste: Torremolinos, Benalmádena, Mijas, Fuengirola, Marbella, Ojén, Istán, Benahavís, Estepona y Casares. En total, se extiende por una superficie de $98.943,4$ ha. Se trata de un espacio geográfico más bien longitudinal, que se extiende a lo largo de $80 \mathrm{~km}$, desde la desembocadura del río Guadalhorce, al oeste de la ciudad de Málaga, hasta el Campo de Gibraltar. Desde el punto de vista del medio físico, es un espacio constreñido entre una estrecha llanura litoral, en algunos sectores inexistentes, y un traspaís de marcado carácter montañoso que la aísla y le confiere su benignidad climática, que la hace tan atractiva para la actividad turística durante todo el año. En general, las alineaciones montañosas se disponen de forma paralela a la costa, alcanzando alturas y pendientes superiores a los $1.000 \mathrm{~m}$ y al $25 \%$, respectivamente, de forma generalizada. Entre esta orla montañosa y el litoral, aparece un piedemonte que desciende más suavemente hacia el mar, ocupado intensivamente por la urbanización y las infraestructuras terrestres.

Concerniente a los usos del suelo, según los datos de 2012 en los Datos Espaciales de Referencia de Andalucía (DERA), la mayor parte de la comarca lo compone la vegetación arbustiva y/o herbácea, seguido de pequeñas áreas de bosque distribuidas por las áreas de interior, y zonas agrícolas repartidas discontinuamente a lo largo del territorio, en menor medida. Por último, el uso artificial, principalmente suelo urbano, que se distribuye a lo largo de la línea de costa (Figura 2). 
FIGURA 1

Medio físico y municipios de la costa del sol occidental

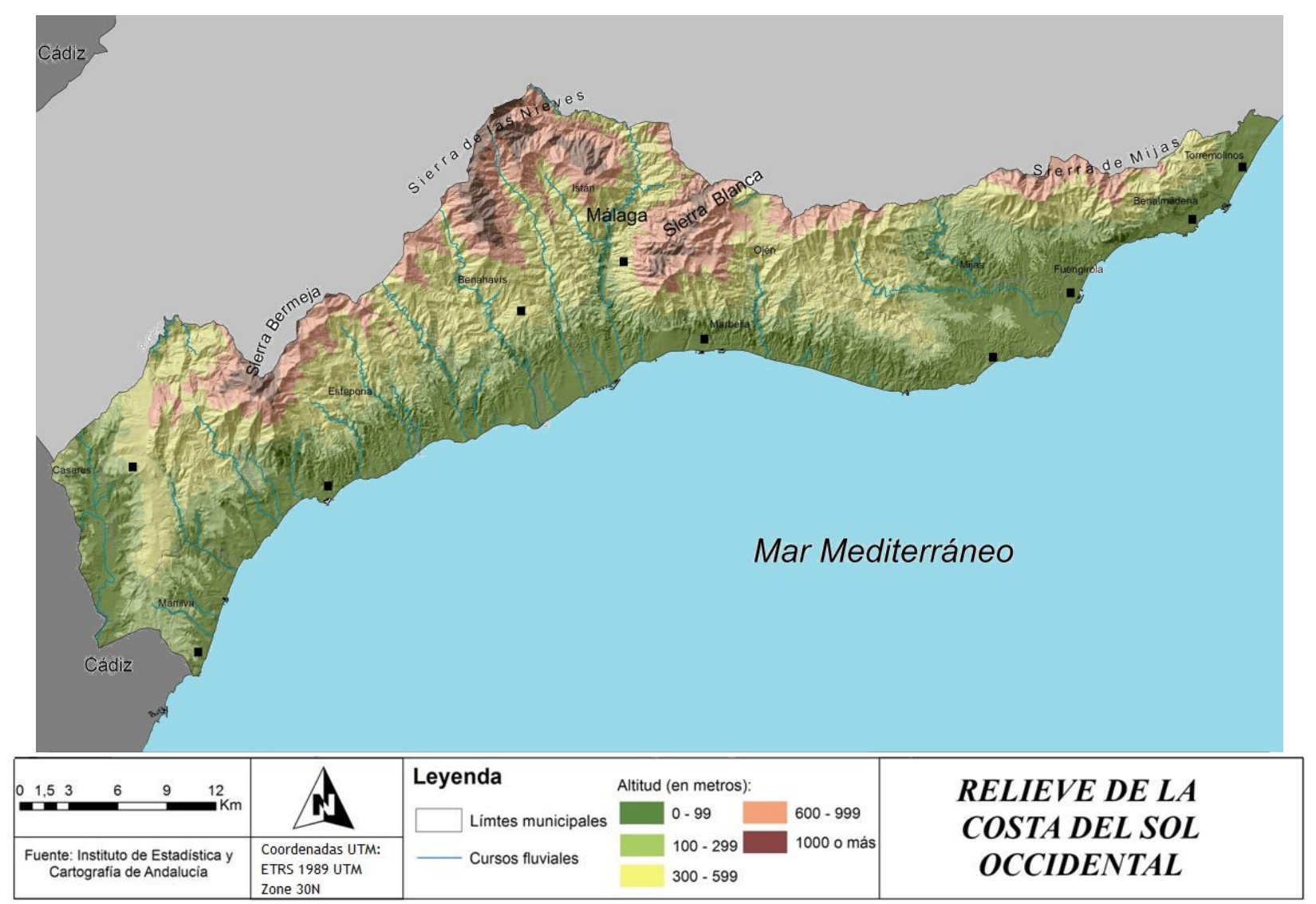

FIGURA 2

Distribución de los usos del suelo en la costa del sol occidental (2012)

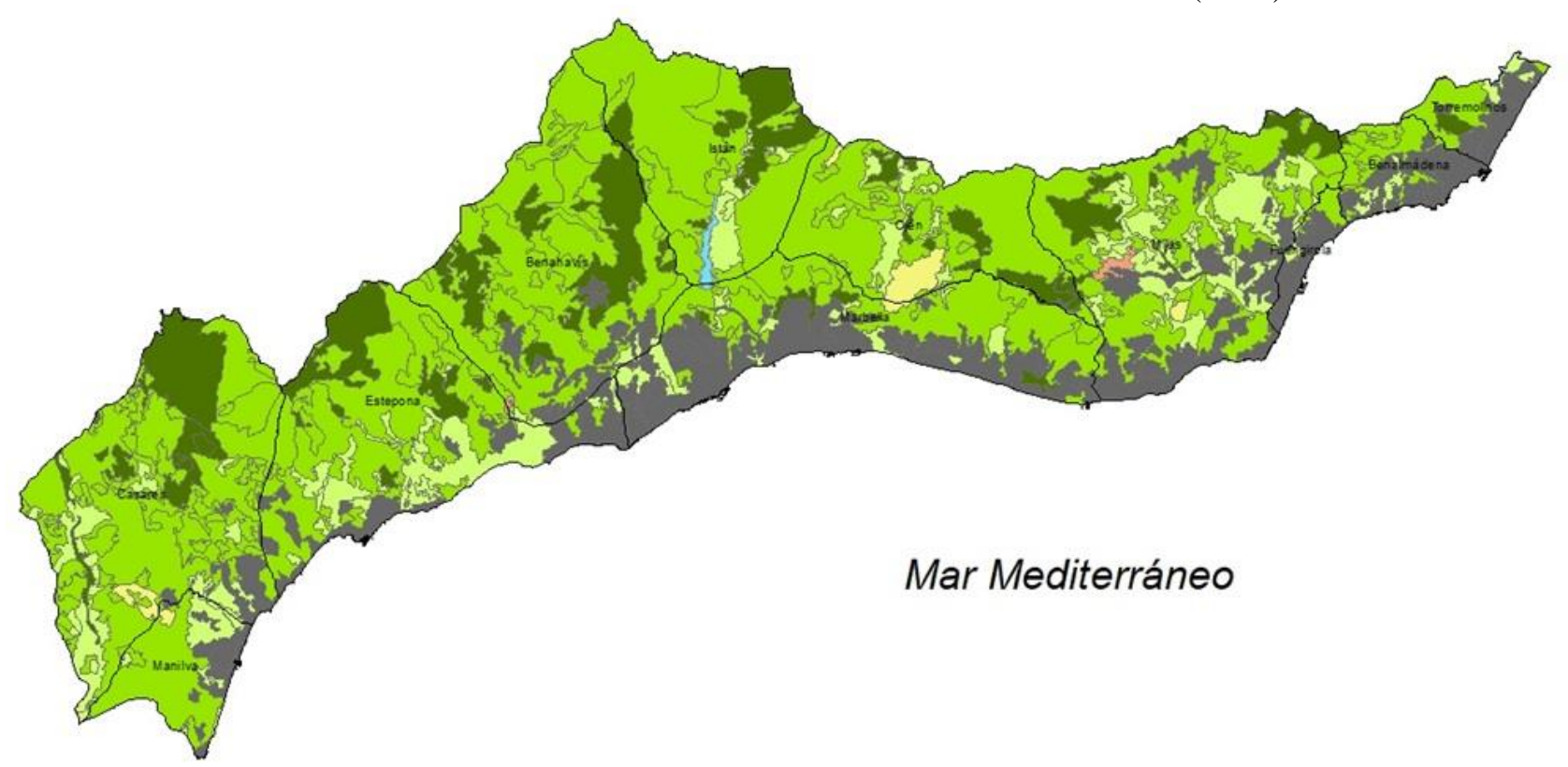

\begin{tabular}{|c|c|c|c|c|}
\hline $\begin{array}{ll}3 & 6\end{array}$ & & Leyenda & Zonas agricolas & \\
\hline$=\mathrm{Km}$ & & $\square$ Limtes municpales & Vegetación escasa & USOS DEL SUELO EN LA COSTA \\
\hline \multirow{2}{*}{$\begin{array}{l}\text { Fuente: Red de Información } \\
\text { Ambiental de Andaluciaa }\end{array}$} & Coordenadas UTM: & $\begin{array}{l}\text { Limite comarcal } \\
\text { Aguas continentales }\end{array}$ & $\begin{array}{l}\text { Vegetación arbustiva yio hert áces } \\
\text { Praderas }\end{array}$ & DEL SOL OCCIDENTAL (2007) \\
\hline & 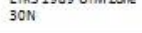 & | Bosques & Zona artificial & \\
\hline
\end{tabular}


Respecto al clima de esta zona de estudio, se encuadra dentro del clima mediterráneo típico Csa, según la clasificación climática de Köppen, en el que se distingue inviernos suaves y veranos secos y calurosos, con una temperatura media estival que ronda los 25 grados centígrados, y con escasas precipitaciones anuales, concentradas principalmente en otoño. Cabe destacar además, que esta zona también suele sufrir las olas de calor que suelen afectar cada verano a la Península Ibérica. Como ejemplo tenemos las 4 y 3 olas de calor sufridas en 1991 y 2012 respectivamente (RODRÍGUEZ BALLESTEROS, 2012).

Este espacio se encuentra, por tanto, masivamente ocupado en la primera línea de playa, en la segunda línea e, incluso, comienza a dar síntomas de una notable ocupación en una tercera línea, en el contacto del piedemonte con la orla montañosa (GÓMEZ ZOTANO et al., 2017). En el conjunto de los municipios de la Costa del Sol occidental, se encuentra censada una población total de 530.384 habitantes según el censo de 2016 (INE). No obstante, a lo largo del año, a esta población censada se suman más de 390.000 y 85.000 turistas alojados en hoteles y apartamentos, respectivamente, para el conjunto de municipios de la Costa del Sol, según datos del Instituto Nacional de Estadística para el año 2016; además, se debe sumar una cifra indeterminada de residentes extranjeros no censados que residen en la zona varios meses al año. En general, esta población, residente y flotante, queda alojada en la primera línea de costa; sin embargo, una buena parte de ella tiene su residencia, permanente o temporal, en la segunda y tercera línea, en áreas de menor densidad urbana, principalmente, urbanizaciones y áreas residenciales esparcidas por el piedemonte y la orla montañosa. Es decir, buena parte de la población de la Costa del Sol occidental vive en áreas urbanizadas. Como se puede observar en ambas fotografías, es habitual encontrar ejemplos como los indicados en la figura 3: segundas residencias unifamiliares y urbanizaciones dispersas, a veces, inconexas, en terrenos de carácter eminentemente forestal, que se extienden por áreas afectadas en algún momento por el fuego; en ambas fotos se recogen ejemplos de áreas afectadas por el gran incendio de Barranco Blanco de agosto de 2012. Un dato significativo es el incremento en la superficie urbanizada desde los años noventa del siglo XX hasta 2007, momento en el que comienza la crisis de la construcción (Figura 4). Si se atiende al total de superficie parcelada edificada de la Costa del Sol Occidental de los resultados que ofrece el Ministerio de Hacienda y Administraciones Públicas, se observa un crecimiento constante en el periodo 1995 - 2013, desde las 7.425,4 hectáreas de parcelas construidas a las 10.546,8 has de 2013.

FIGURA 3

Ejemplos de áreas urbanizadas afectadas por incendios forestales recientes.

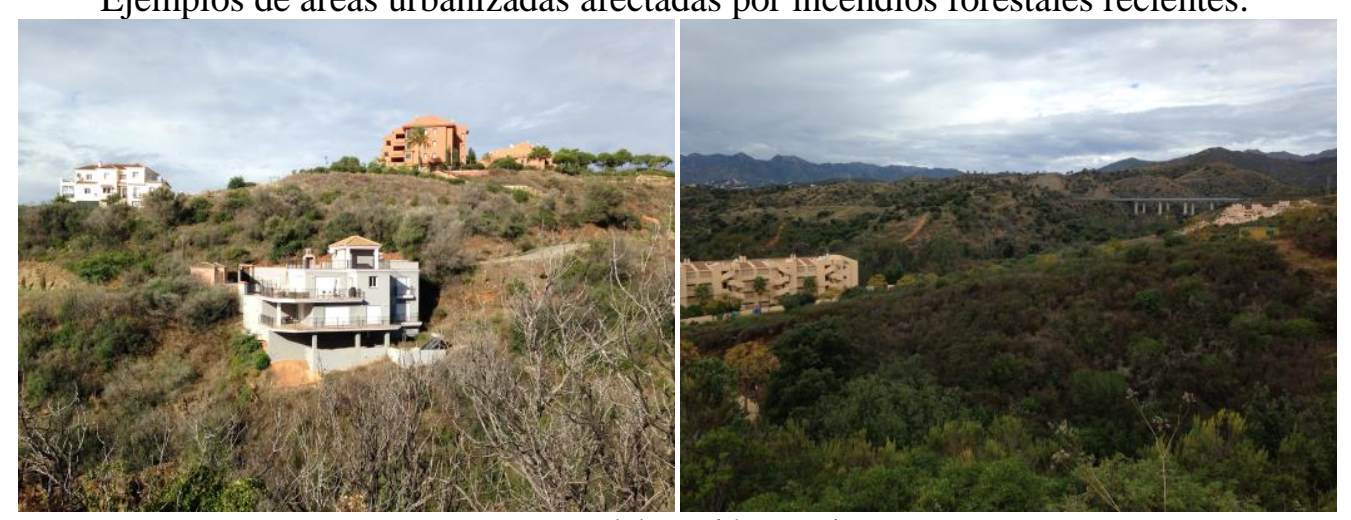

Fuente: elaboración propia. 
FIGURA 4

Evolución de la superficie parcelaria edificada en la costa del sol (1991-2013).

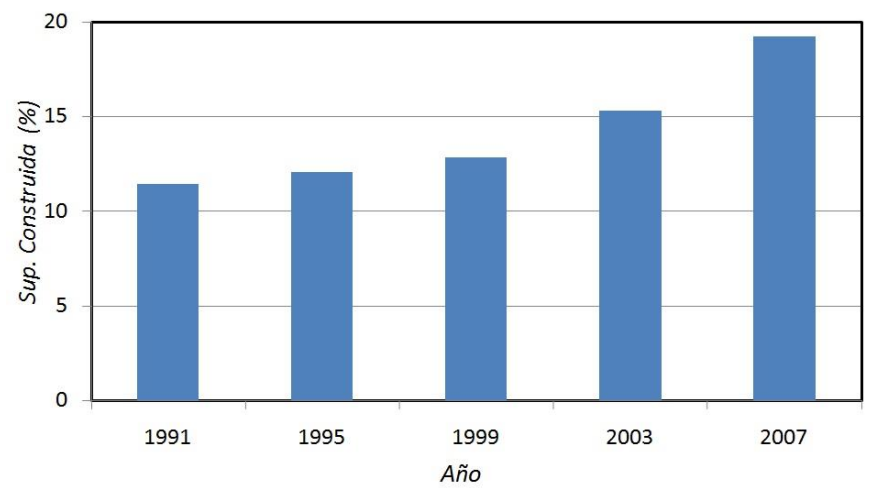

Fuente: Elaboración propia a partir de los datos del Ministerio de Hacienda y Administraciones Públicas.

\section{METODOLOGÍA}

\subsection{FUENTES DE INFORMACIÓN}

La información geográfica de base física y humana para el desarrollo de este trabajo ha sido tomada del Instituto de Estadística y Cartografía de Andalucía (Datos Espaciales de Referencia de Andalucía, DERA) utilizando las capas de relieve (rl04_inter_altimetria), límites administrativos (13_01_TerminoMunicipal) y usos del suelo (06_01_UsoSuelo) e infraestructuras viarias (09_14_RedCarreteras), mientras que de la Red de Información Ambiental de Andalucía (REDIAM) se ha extraído la información urbana de las capas MUCVA25. La información base sobre la naturaleza y dinámica de los incendios forestales en el ámbito de estudio de este trabajo se ha obtenido a partir de los datos anuales y de la cartografía histórica de incendios del Plan INFOCA, perteneciente a la Consejería de Medio Ambiente y Territorio de la Junta de Andalucía, correspondiente a la provincia de Málaga para el periodo 1987-2015. Respecto a los datos de la dinámica de siniestros en otras áreas turísticas del mediterráneo español, estos se han obtenido a través de la información que proporciona el Ministerio de Agricultura, Pesca, Alimentación y Medio Ambiente del Gobierno de España por medio de los informes "Los incendios forestales en España" disponibles en su web (MAPAMA). Para los datos de superficie parcelada edificada en la comarca se han consultado los datos que ofrece el Ministerio de Hacienda y Administraciones Públicas.

\subsection{ANÁLISIS DE LA DINÁMICA TERRITORIAL DE LOS INCENDIOS FORESTALES}

Para realizar el análisis de la dinámica territorial de los incendios forestales en la comarca de estudio se han utilizado las capas vectoriales de la cartografía histórica de incendios para la provincia de Málaga, utilizando el número de hectáreas (superficie afectada), municipio (lugar del siniestro) y año (fecha del siniestro) que proporciona la Consejería de Medio Ambiente y Ordenación del Territorio de la Junta de Andalucía a través del portal REDIAM para el intervalo 1987-2015. Estas capas vectoriales se han cargado en el programa ArcGis 10.3 (Licencia Corporativa de la Universidad de Málaga) y se ha procedido a separar la información referente al área provincial de Málaga de la comarcal de estudio en dos capas diferentes. A cada una de ellas se le ha extraído la información de su tabla de atributos y llevado a una hoja de cálculo, calculando previamente su área afectada total de cada una de ellas, de modo que quede reflejado, en el caso de la comarca de la Costa del Sol Occidental, tanto la superficie de siniestros que se originó en el propio municipio, como la superficie afectada en el municipio de siniestros originados en el exterior del mismo.

Una vez separados los datos en diferentes escalas - provincia de Málaga y comarca de la Costa del Sol occidental-, se ha procedido a desagregar los datos según la extensión del área afectada (en conatos, de <0,5 ha, e incendios pequeños, medianos y grandes, de 0,5 a 1 Ha., de 1 a 100 Ha. y de más 100 Ha., respectivamente) y por año. Tras esta clasificación de los datos obtuvo el total de número de siniestros, por tipo y superficie afectada.

Posteriormente se ha procedido a seleccionar de todo el periodo de estudio, los años 1991, 1995, 1999, 2003, 2007, y 2013: estos años han sido seleccionados porque existía cartografía digital de los usos del suelo, áreas urbanizadas e infraestructuras terrestres para los mismos haciendo posible la comparación con las áreas 
afectadas por el fuego en esos años. Además, se seleccionó también el año 2012 por su especial virulencia en la zona de estudio al tener lugar el siniestro de mayor superficie quemada para el periodo de estudio. Ello ha propiciado su comparación con otras áreas turísticas del mediterráneo español -con los datos obtenidos del Ministerio de Agricultura, Pesca, Alimentación y Medio Ambiente-, y su análisis temporal, tanto en dinámica de incendios como en afección en las áreas urbanizadas.

Por último, con el objetivo de evaluar las diferencias significativas entre años respecto a la superficie quemada y al número de incendios, se realizó el siguiente análisis estadístico: i) test de Levene para comprobar la distribución paramétrica de los datos; y ii) test no paramértrico de Mann-Kendall. Este procedimiento se realizó mediante el software IBM SPSS Statistics 25.

\subsection{ANÁLISIS DE LA AFECCIÓN EN LAS ÁREAS URBANIZADAS}

Por último, se elaboró la cartografía de las áreas de influencia de los incendios forestales y su afección a las áreas urbanas de la Costa del Sol. Para la realización de esta cartografía -elaborada con el programa informático ArcGis 10.3- se tomó en cuenta la capa de superficie total quemada para cada uno de los años mencionados en el apartado anterior y se utilizó la herramienta "Buffering", consistente en generar una capa con un perímetro asignado desde el límite de la capa de superficie quemada. Se han asignado 5 perímetros o áreas de influencia $(0,100,500,1.000$ y $2.000 \mathrm{~m})$, generando sus correspondientes capas vectoriales. A continuación, se ha incluido para cada uno de los mapas la capa temática correspondiente al área urbana de la comarca para cada año, y se ha ejecutado la herramienta de geoprocesamiento "Intersect", en el que se crea una nueva capa con las entidades que se superponen, para cada uno de los perímetros generados. Finalmente, se han unido estas capas con la herramienta de geoprocesamiento "Union", y se le ha otorgado una gama de colores para su correcta identificación. Finalmente, se procedió a calcular la superficie urbanizada afectada por el fuego en cada uno de los intervalos de influencia para cada año analizado.

\section{RESULTADOS Y DISCUSIÓN}

\subsection{DINÁMICA TERRITORIAL DE LOS INCENDIOS FORESTALES EN LA COSTA DEL SOL}

Durante el periodo estudiado (1987-2015) se han producido un total de 425 siniestros en el conjunto de municipios de la Costa del Sol Occidental, calcinando más de 32.000 ha, como se recoge en la Tabla 1. Estos 425 siniestros se reparten en 148 conatos y 277 incendios, arrasando 48,2 y 32.297 hectáreas, respectivamente. De entre los incendios, han sido los considerados "pequeños" los más numerosos, con un total de 141, aunque los que más superficie han quemado han sido los clasificados como "grandes", con cerca de 22.000 ha, lo que supone el 68\% del total de superficie calcinada (Figura 5). En dicho periodo, el municipio más afectado por el fuego ha sido Mijas, con 95 siniestros y cerca de 4.000 ha afectadas, seguido de Casares con 77 siniestros y algo más de 3.800 ha. En términos relativos, los municipios más afectados por el fuego han sido en este orden: Manilva (33,8\%), Mijas (26,8\%), Marbella (26,1\%), Casares (23,6\%), Estepona (18,2\%), Ojén (17,5\%), Benahavís $(9,7 \%)$, Benalmádena (4,6\%), Istán $(1,8 \%)$, Torremolinos $(1,8 \%)$ y Fuengirola $(0,9 \%)$. Estas cifras indican el porcentaje de superficie de cada uno de los municipios que se han quemado al menos una vez.

TABLA 1

$\mathrm{N}^{\circ}$ de siniestros y superficie afectada según su tipo en la costa del sol occidental (1987-2015)

\begin{tabular}{|c|c|c|c|c|c|c|c|c|c|c|c|c|}
\hline \multirow{3}{*}{ MUNICIPIO } & \multicolumn{6}{|c|}{ SINIESTROS } & \multicolumn{6}{|c|}{ INCENDIOS SEGÚN TAMAÑO } \\
\hline & \multicolumn{2}{|c|}{ TOTAL } & \multicolumn{2}{|c|}{ CONATOS } & \multicolumn{2}{|c|}{ INCENDIOS } & \multicolumn{2}{|c|}{ Pequeños } & \multicolumn{2}{|c|}{ Medianos } & \multicolumn{2}{|c|}{ Grandes } \\
\hline & $\mathrm{N}^{\mathrm{o}}$ & $\mathrm{Ha}$ & $\mathrm{N}^{\mathrm{o}}$ & $\mathrm{Ha}$ & $\mathrm{N}^{\mathrm{o}}$ & $\mathrm{Ha}$ & $\mathrm{N}^{\circ}$ & $\mathrm{Ha}$ & $\mathrm{N}^{\mathrm{o}}$ & $\mathrm{Ha}$ & $\mathrm{N}^{\mathrm{o}}$ & $\mathrm{Ha}$ \\
\hline BENAHAVÍS & 38 & $1.404,2$ & 11 & 4 & 27 & $1.400,1$ & 12 & 46,6 & 15 & 1.354 & 0 & 0 \\
\hline BENALMÁDENA & 8 & 123,0 & 4 & 1,2 & 4 & 121,8 & 1 & 1,8 & 3 & 120 & 0 & 0 \\
\hline CASARES & 77 & $3.836,5$ & 20 & 6,7 & 57 & $3.829,9$ & 30 & 110,1 & 25 & 2.375 & 2 & 1.345 \\
\hline ESTEPONA & 70 & $2.502,2$ & 25 & 8,8 & 45 & $2.493,3$ & 23 & 75,4 & 20 & 1.367 & 2 & $1.049,5$ \\
\hline FUENGIROLA & 5 & 9,1 & 2 & 0,3 & 3 & 8,8 & 3 & 8,8 & 0 & 0 & 0 & 0 \\
\hline ISTÁN & 13 & 174,2 & 8 & 2,4 & 5 & 171,8 & 1 & 8,2 & 4 & 163,5 & 0 & 0 \\
\hline MANILVA & 24 & $1.204,1$ & 4 & 2 & 20 & $1.202,1$ & 12 & 36,4 & 7 & 278,9 & 1 & 886,8 \\
\hline MARBELLA & 46 & $3.050,7$ & 19 & 6,3 & 27 & $3.044,3$ & 13 & 47,3 & 12 & 1.610 & 2 & $1.386,9$ \\
\hline
\end{tabular}




\begin{tabular}{|l|l|l|l|l|l|l|l|l|l|l|l|l|}
\hline MIJAS & 95 & $3.982,3$ & 39 & 12,5 & 56 & $3.969,8$ & 28 & 108,8 & 26 & 1.046 & 2 & $2.815,2$ \\
\hline OJÉN & 36 & $1.502,8$ & 12 & 3,1 & 24 & $1.499,7$ & 13 & 42,2 & 11 & 1.458 & 0 & 0 \\
\hline TORREMOLINOS & 7 & 35,4 & 3 & 0,9 & 4 & 34,5 & 3 & 6,9 & 1 & 27,6 & 0 & 0 \\
\hline $\begin{array}{l}\text { MUNICIPIOS } \\
\text { EXTERIORES* }\end{array}$ & 6 & $14.520,9$ & 1 & 0 & 5 & 14.521 & 2 & 13,6 & 0 & 0 & 3 & 14.507 \\
\hline TOTAL & 425 & $32.345,3$ & 148 & 48,2 & 277 & 32.297 & 141 & 506,1 & 124 & 9.800 & 12 & 21.991 \\
\hline
\end{tabular}

Fuente: Elaboración propia a partir de datos de la Consejería de Medio Ambiente y Territorio de la Junta de Andalucía.

En la figura 4, se puede observar que han sido las tres áreas principales donde se han concentrado los siniestros. Así, las áreas más afectadas de la comarca son: extremo occidental, donde se encuentran los municipios de Casares, Manilva y oeste de Estepona; área central-este, focalizado en la mitad este del municipio de Ojén, este de Marbella y Mijas; y, por último, en el área centro-norte, concretamente en el norte del municipio de Benahavís y noroeste de Istán, en contacto con la comarca de la Serranía de Ronda. En general, las principales áreas arrasadas por las llamas se encuentran retiradas de la línea de costa, adentrándose en zonas de mayor altitud -por encima de los 300 metros- y más cercanas a las zonas con más carácter montañoso, si bien, numerosos conatos y otros incendios ocurren por debajo de esta altitud, localizados en un espacio caracterizado por la urbanización intensiva.

FIGURA 5

Distribución espacial del área afectada por los incendios forestales en la costa del sol (1987-2015)

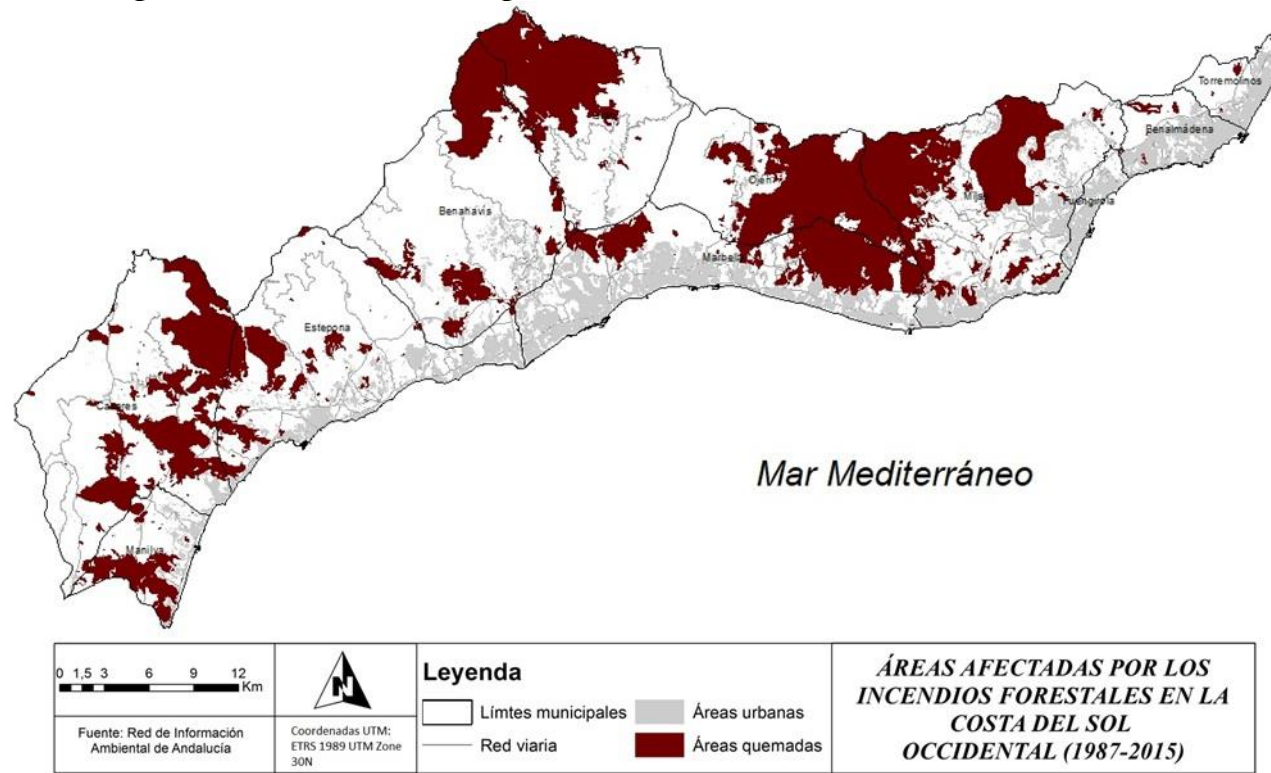

Fuente: Elaboración propia a partir de datos obtenidos de Red de Información Ambiental de Andalucía (REDIAM)

Respecto a la evolución temporal en el número de siniestros afectados en el área de estudio (Figura 6), se observa, por un lado, que el número de incendios desde 1987 hasta 2015 ha tenido un progreso irregular, aunque hay un claro comportamiento ascendente desde el año 1997 hasta 2015, con una importante subida registrada en 2009, es decir, a lo largo de los años en los que la superficie construida crece notablemente en la Costa del Sol occidental. Por otro lado, en número de conatos, se pasa de un registro nulo desde 1987 hasta el año 2000 (inexistentes debido a que los sistemas de detección de focos de incendios no estaban aún establecidos por el Plan INFOCA, en la comunidad autónoma andaluza, haciendo que rápidamente los siniestros adquirieran carácter de incendio). A partir del año 2000, se inicia una trayectoria irregular pero también ascendente hasta 2015, con un significativo pico anotado el año 2012. Estos datos fueron sometidos a un análisis estadístico para evaluar las diferencias significativas entre años. Una vez que el test de Levene corroboró la distribución de los datos era no paramétrica tanto para la superficie quemada anual, como para el número de incendios ( $\mathrm{p}<0,05$ en ambos casos), se aplicó el test de Mann-Kendall. El resultado indicó que existían diferencias significativas entre años respecto a la superficie quemada $(\mathrm{p}=0,038)$ y tanto al número de incendios $(\mathrm{p}=0,022)$ como al de conatos $(\mathrm{p}=0,045)$. 
Asimismo, en la figura 7, se representa la superficie afectada por el fuego en cada uno de los años de estudio seleccionado, así como la superficie urbanizada para cada uno de ellos. En esta cartografía, se puede observar con claridad las áreas más afectadas en cada uno de los años, siendo 1991 y 2012 los años que más superficie fueron afectadas por las llamas, así como a largo del periodo de estudio, los siniestros van desplazándose ligeramente hacia las áreas urbanas consolidadas, más cercanas al litoral.

FIGURA 6

Evolución de la superficie afectada y número de siniestros en la costa del sol occidental durante el periodo 1987- 2015.

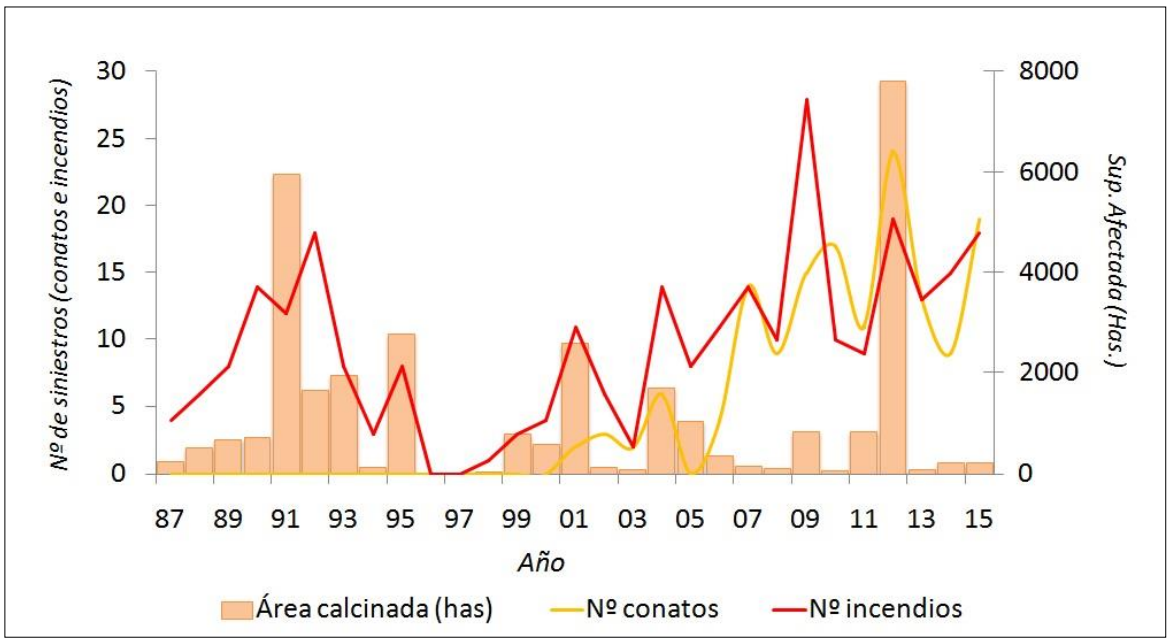

Fuente: Elaboración propia a partir de datos obtenidos de Red de Información Ambiental de Andalucía (REDIAM)

FIGURA 7

Evolución áreas afectadas por incendios en la costa del sol occidental (1991- 2013)

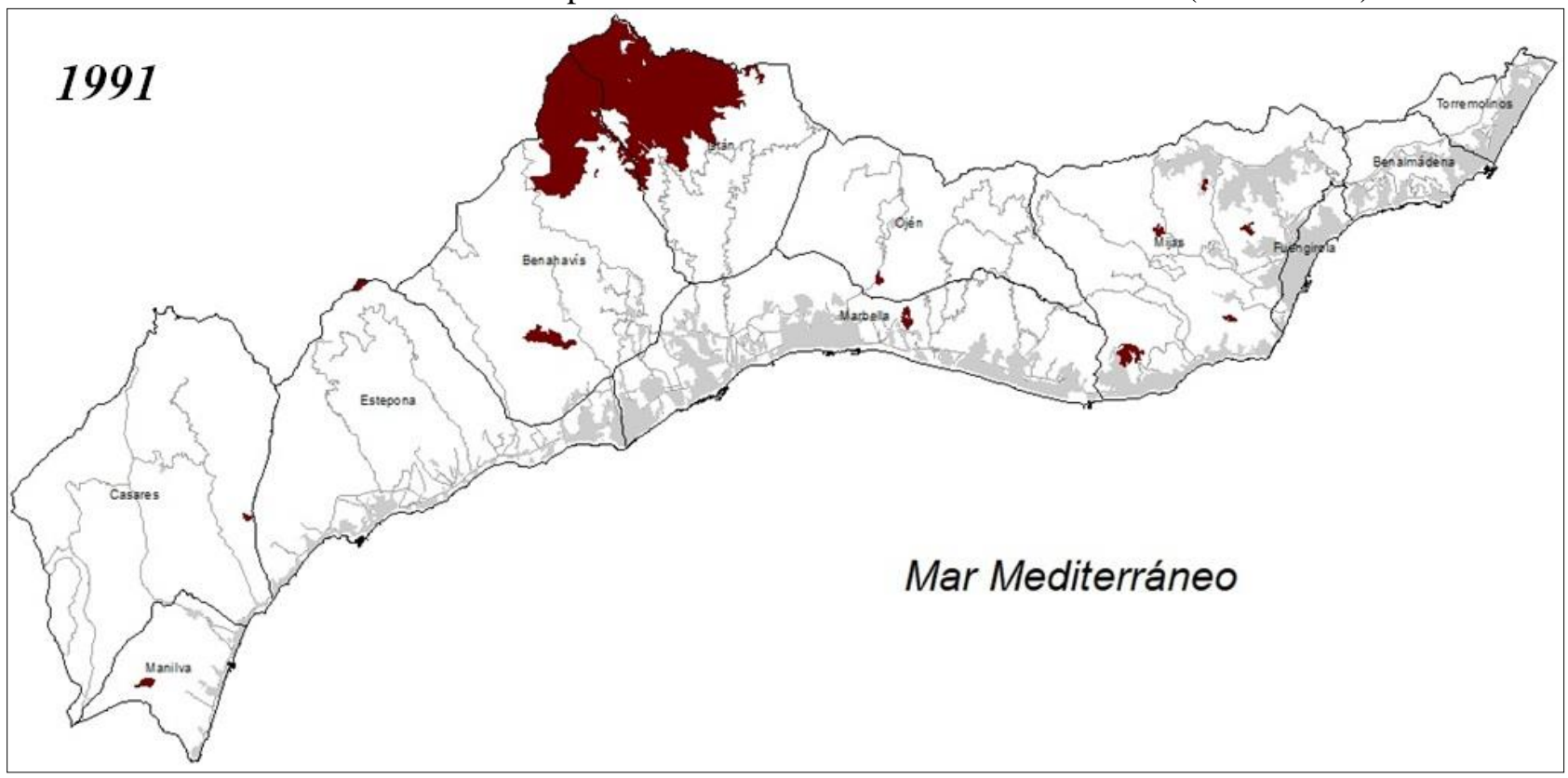



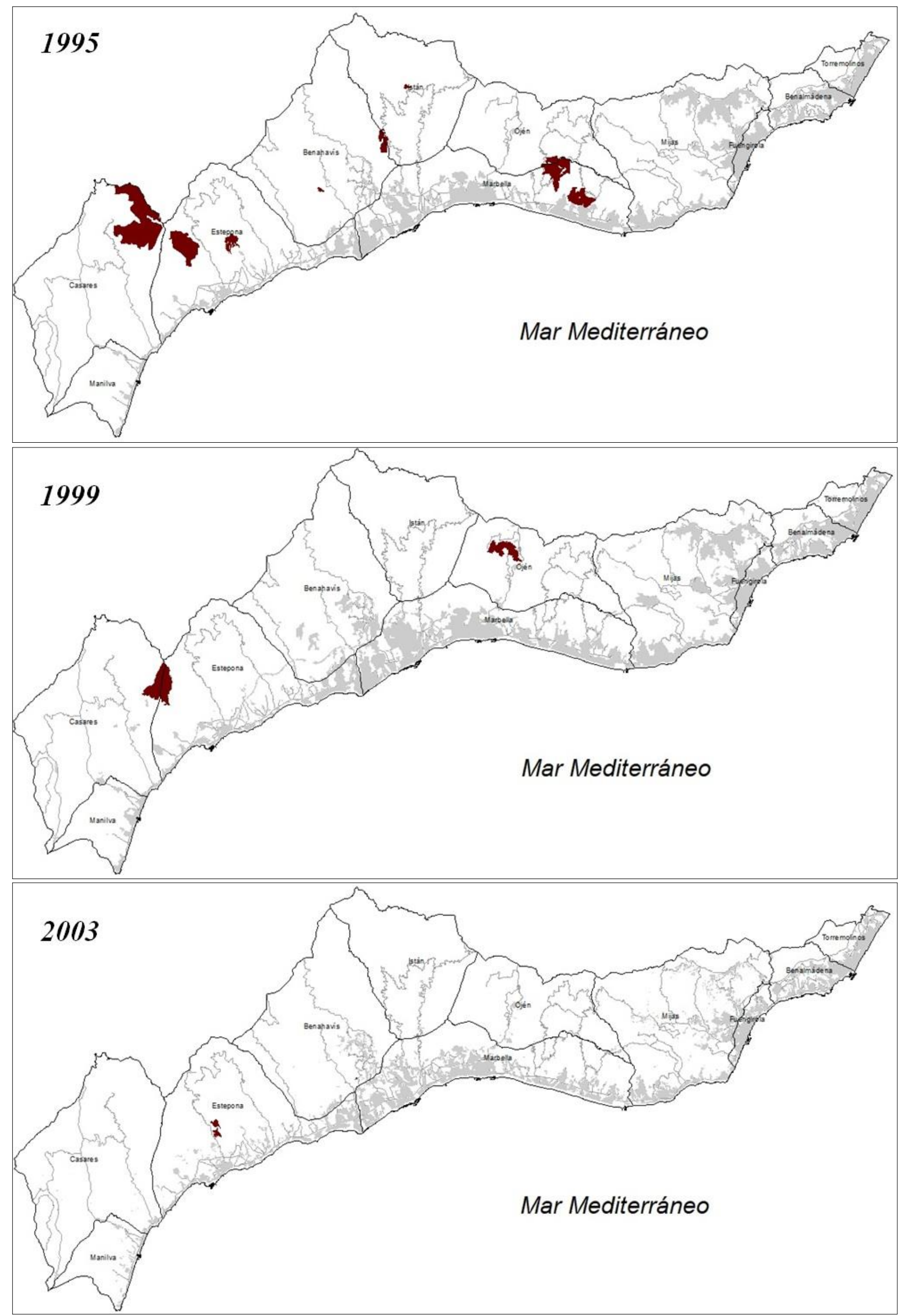


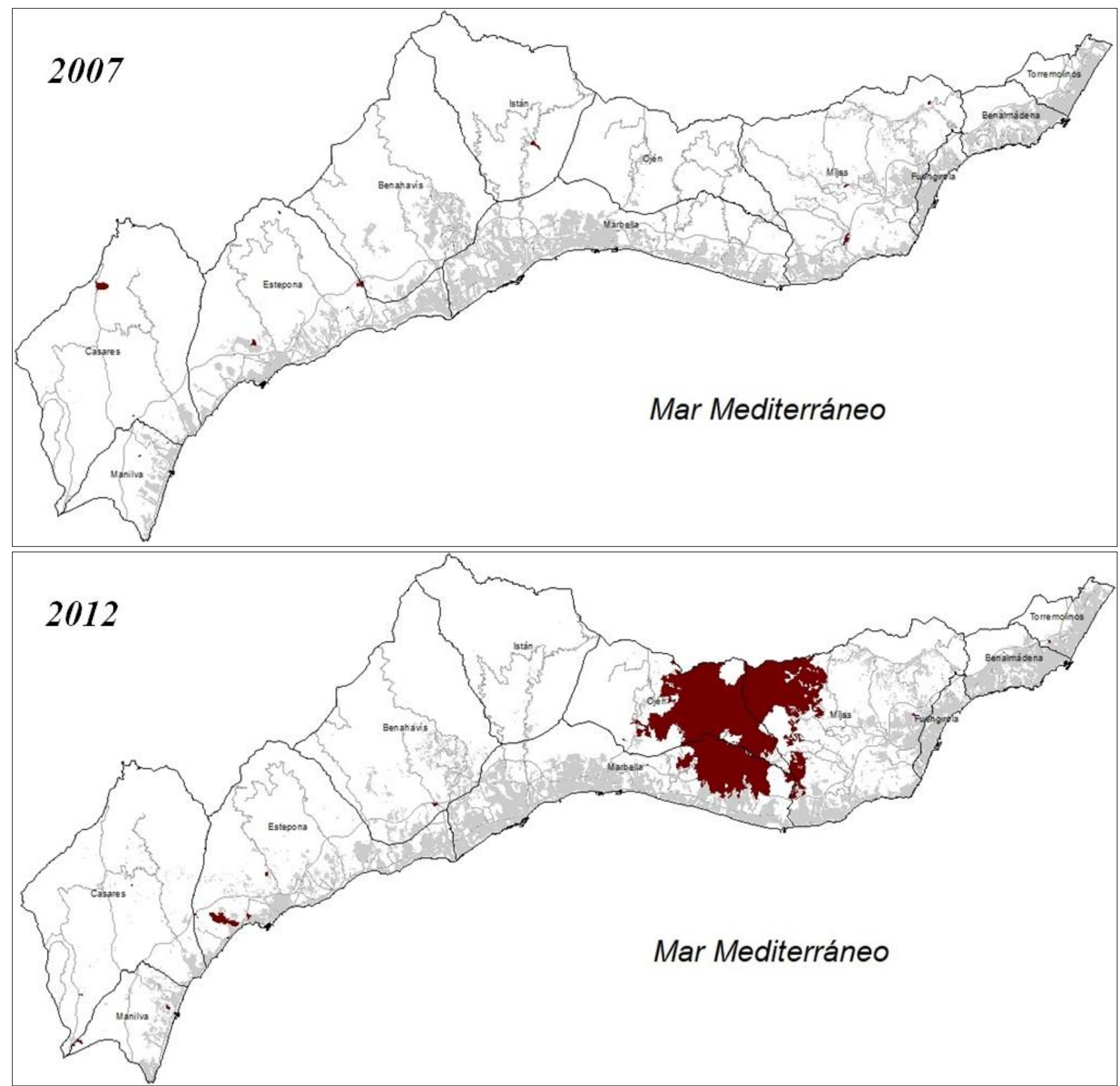




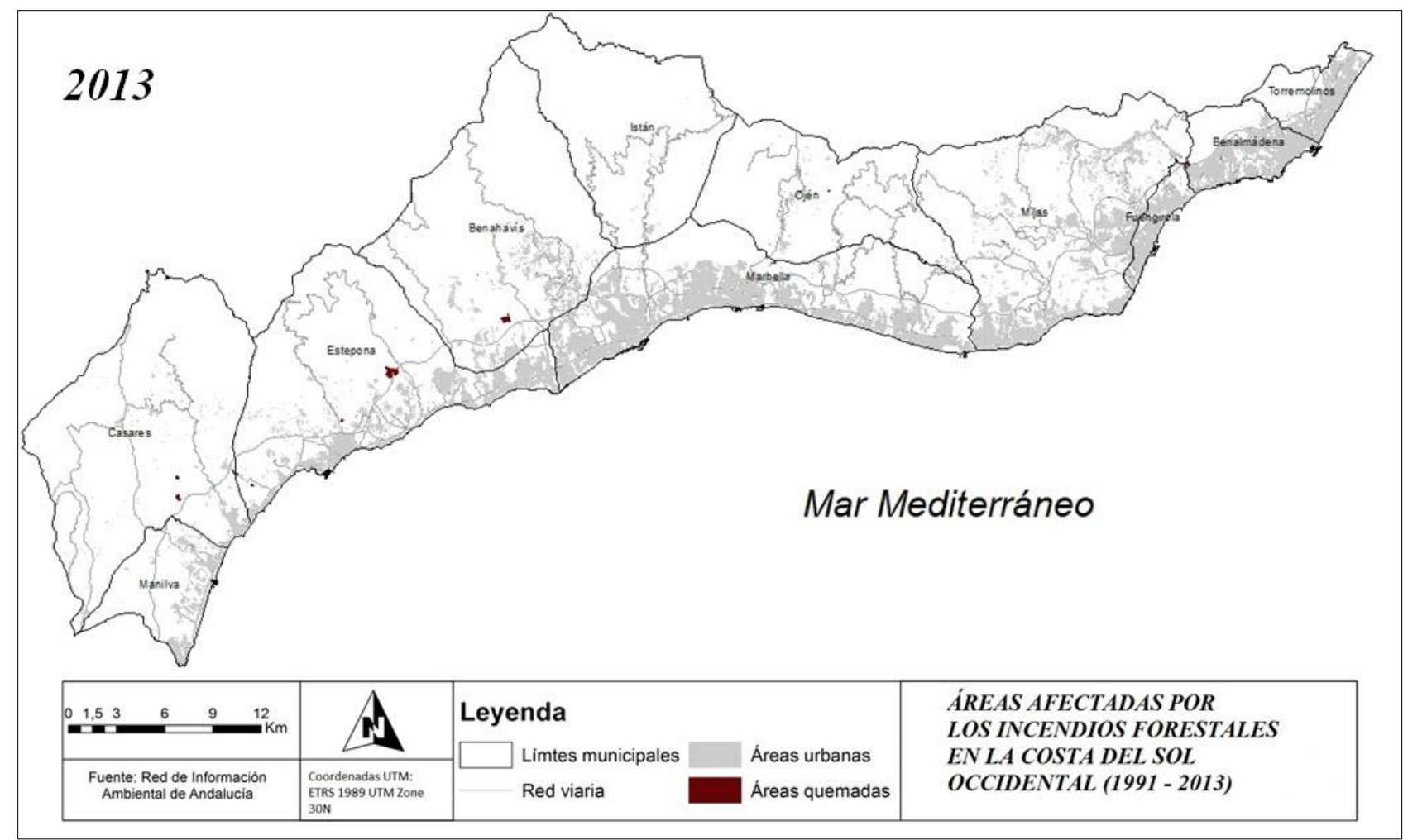

Fuente: Elaboración propia a partir de datos obtenidos de Red de Información Ambiental de Andalucía (REDIAM).

Desde una aproximación comarcal, estos datos suponen un importante porcentaje de los siniestros ocurridos en la provincia de Málaga, superando algunos años el $40 \%$ del número total de siniestros registrados (Tabla 2). Si se comparan los datos totales de la provincia de Málaga con otras áreas turísticas españolas, se observa que hasta 2007 este fenómeno incidía en menor cantidad en el caso malagueño, año desde el cual invirtió este carácter de manera bastante significativa, pasando de menos 100 siniestros en años anteriores a más de 100 en años posteriores.

TABLA 2

Evolución temporal del $\mathrm{n}^{\mathrm{o}}$ de siniestros en el conjunto de la costa del sol y comparación con otras áreas turísticas españolas.

\begin{tabular}{|c|c|c|c|c|c|c|c|c|c|c|c|c|}
\hline \multirow{2}{*}{ Año } & \multirow{2}{*}{$\begin{array}{l}\text { Tipo de } \\
\text { siniestro }\end{array}$} & \multicolumn{11}{|c|}{ Área territorial } \\
\hline & & $\mathrm{CSO}$ & $\mathrm{CSO}(\%)$ & MA & B & GI & LL & $\mathrm{T}$ & A & CS & $\mathrm{V}$ & IB \\
\hline \multirow{3}{*}{1991} & Conato & 0 & 0 & 0 & 241 & 87 & 43 & 74 & 102 & 125 & 181 & 94 \\
\hline & Incendio & 12 & 41,4 & 29 & 125 & 42 & 75 & 94 & 157 & 127 & 177 & 37 \\
\hline & Total & 12 & 41,4 & 29 & 366 & 129 & 118 & 168 & 259 & 252 & 358 & 131 \\
\hline \multirow{3}{*}{1995} & Conato & 0 & 0 & 0 & 228 & 189 & 37 & 138 & 53 & 67 & 172 & 97 \\
\hline & Incendio & 8 & 66,7 & 12 & 46 & 27 & 35 & 53 & 44 & 35 & 75 & 19 \\
\hline & Total & 8 & 66,7 & 12 & 274 & 216 & 72 & 191 & 97 & 102 & 247 & 116 \\
\hline \multirow{3}{*}{1999} & Conato & 0 & 0 & 8 & 315 & 176 & 76 & 104 & 126 & 132 & 160 & 114 \\
\hline & Incendio & 3 & 27,3 & 11 & 61 & 22 & 54 & 35 & 57 & 32 & 72 & 38 \\
\hline & Total & 3 & 15,8 & 19 & 376 & 198 & 130 & 139 & 183 & 164 & 232 & 152 \\
\hline \multirow{3}{*}{2003} & Conato & 2 & 7,7 & 26 & 276 & 136 & 95 & 60 & 91 & 67 & 165 & 111 \\
\hline & Incendio & 2 & 5,6 & 36 & 56 & 29 & 36 & 15 & 33 & 21 & 31 & 16 \\
\hline & Total & 4 & 6,5 & 62 & 332 & 165 & 131 & 75 & 124 & 88 & 196 & 127 \\
\hline \multirow{3}{*}{2007} & Conato & 14 & 26,4 & 53 & 179 & 154 & 72 & 85 & 63 & 84 & 137 & 106 \\
\hline & Incendio & 14 & 23,0 & 61 & 24 & 11 & 20 & 34 & 28 & 30 & 33 & 7 \\
\hline & Total & 28 & 24,6 & 114 & 203 & 165 & 92 & 119 & 91 & 114 & 170 & 113 \\
\hline
\end{tabular}




\begin{tabular}{|c|c|c|c|c|c|c|c|c|c|c|c|c|}
\hline \multirow{2}{*}{ Año } & \multirow{2}{*}{$\begin{array}{l}\text { Tipo de } \\
\text { siniestro }\end{array}$} & \multicolumn{11}{|c|}{ Área territorial } \\
\hline & & CSO & $\mathrm{CSO}(\%)$ & MA & B & GI & LL & $\mathrm{T}$ & A & CS & $\mathrm{V}$ & IB \\
\hline \multirow{3}{*}{2012} & Conato & 24 & 29,6 & 81 & 292 & 107 & 125 & 119 & 93 & 68 & 185 & 111 \\
\hline & Incendio & 19 & 31,1 & 61 & 23 & 17 & 41 & 24 & 37 & 20 & 64 & 36 \\
\hline & Total & 43 & 30,3 & 142 & 315 & 124 & 166 & 143 & 130 & 88 & 249 & 147 \\
\hline \multirow{3}{*}{2013} & Conato & 13 & 15,1 & 86 & 275 & 94 & 79 & 106 & 72 & 47 & 152 & 81 \\
\hline & Incendio & 13 & 18,6 & 70 & 13 & 9 & 11 & 15 & 21 & 23 & 20 & 9 \\
\hline & Total & 26 & 16,7 & 156 & 288 & 103 & 90 & 121 & 93 & 70 & 172 & 90 \\
\hline
\end{tabular}

Nota: CSO, Costa del Sol Occidental; CSO (\%), porcentaje respecto al total provincial; MA, Málaga; B, Barcelona; GI, Girona; LL, Lleida; T, Tarragona; CS, Castellón; V, Valencia; A, Alicante; IB, Islas Baleares.

Fuente: Elaboración propia a partir de los datos obtenidos de la Red de Información Ambiental de Andalucía y el Ministerio de Agricultura, Pesca, Alimentación y Medio Ambiente

Con respecto a la superficie afectada,

que incluye tanto la provocada por conatos como por incendios, la Costa del Sol Occidental ha acaparado más del 50\% del total de la superficie calcinada en la provincia de Málaga, e incluso en algunos años como 2003, 2007 y 2012 y 2013, alcanzando una cuota cercana al 80\%. Para los años seleccionados, si se compara el caso de Málaga provincia con otras áreas mediterráneas, se observa que se encuentra entre las provincias con mayor número de hectáreas arrasadas por las llamas, a excepción de algún año como 2003. Además, sólo el caso de la comarca de la Costa del Sol Occidental logra superar en superficie afectada a áreas de mayor extensión territorial en muchos de los años observados (Tabla 3).

TABLA 3

Evolución temporal de la superficie afectada (has) en el conjunto de la costa del sol y comparación con otras áreas turísticas españolas.

\begin{tabular}{|l|l|l|l|l|l|l|l|}
\hline & & & \\
Área territorial & 1991 & 1995 & 1999 & 2003 & 2007 & 2012 & 2013 \\
\hline $\begin{array}{l}\text { Costa del Sol } \\
\text { Occidental }\end{array}$ & $5.969,9$ & $2.793,2$ & 798,0 & 71,83 & 144,0 & $7.812,3$ & 93,8 \\
\hline CSO (\% provincial) & 54 & 69 & 66,4 & 9,3 & 15,9 & 79,1 & 14,2 \\
\hline Málaga & $11.060,6$ & $4.049,9$ & $1.202,6$ & 775,3 & 903,2 & $9.878,5$ & 658,6 \\
\hline Barcelona & 737 & 435 & 219,63 & $6.124,4$ & 526,8 & $1.129,9$ & 141,5 \\
\hline Girona & 322 & 347,6 & 260,2 & $2.483,7$ & 139,6 & $9.603,1$ & 543,5 \\
\hline Lleida & 600 & 221,8 & 225,7 & $3.778,9$ & 192,9 & 1119,0 & 65,5 \\
\hline Tarragona & 3763 & $6.035,3$ & 545,6 & 362,53 & $1.189,3$ & $3.174,9$ & 309,7 \\
\hline Alicante & $5.222,2$ & $1.036,7$ & $1.341,8$ & $1.040,7$ & 115,0 & $1.486,7$ & 120,8 \\
\hline Castellón & $1.986,3$ & 721,2 & 859,5 & 369,6 & $9.591,0$ & $11.015,1$ & 260,8 \\
\hline Valencia & $36.217,8$ & 462,5 & $6.356,5$ & $1.949,2$ & 366,2 & $44.429,6$ & $1.061,3$ \\
\hline Islas Baleares & 482,7 & 424,7 & $4.145,2$ & 223,52 & 127,4 & 404,7 & $2.845,5$ \\
\hline
\end{tabular}

Fuente: Elaboración propia a partir de datos obtenidos de la Red de Información Ambiental de Andalucía y el Ministerio de Agricultura, Pesca, Alimentación y Medio Ambiente.

\subsection{AFECCIÓN DE LOS INCENDIOS FORESTALES EN ÁREAS URBANIZADAS}

En los años de estudio, se ha comprobado que los siniestros derivados del fuego han tenido lugar tanto en áreas plenamente montañosas y forestales, como en áreas urbanas. Hasta el año 2007, la afección en áreas urbanas era bastante escueta, en el que no se superaba el 10\% las áreas que se encontraron a 1 kilómetro del siniestro (Figura 8). Sin embargo, a partir de 2007, a consecuencia del incremento en la superficie urbanizada desde finales la década de 1990, se observa un aumento de este fenómeno pues las áreas urbanas situadas a 2 kilómetros del siniestro superaron el 20\% del área urbana total de la comarca (más de la mitad en 2012), y los 
que apenas se situaban a $1 \mathrm{~km}$ supusieron en torno al 10\% (más de un 20\% en el año 2012). En el rango de años expuesto, todos los años, excepto en 1999, han sido alcanzadas por el fuego áreas urbanas, aunque ello supuso menos de un 1\% del total de superficie urbanizada. El año 2012 fue el de mayor afección, con el 0,6\% del área urbana comarcal. En la figura 9, se muestra la cartografía en la que se puede observar la distribución espacial de las áreas urbanizadas situadas a diferentes intervalos distancia respecto al siniestro. Claramente, en los últimos años, al incrementarse el tamaño de las áreas urbanas, aumenta también la cercanía al origen de los siniestros y, por tanto, aumenta el riesgo de estar afectado por éstos.

FIGURA 8

Superficie anual afectada por el fuego en las cercanías de las áreas urbanizadas (1991-2013)

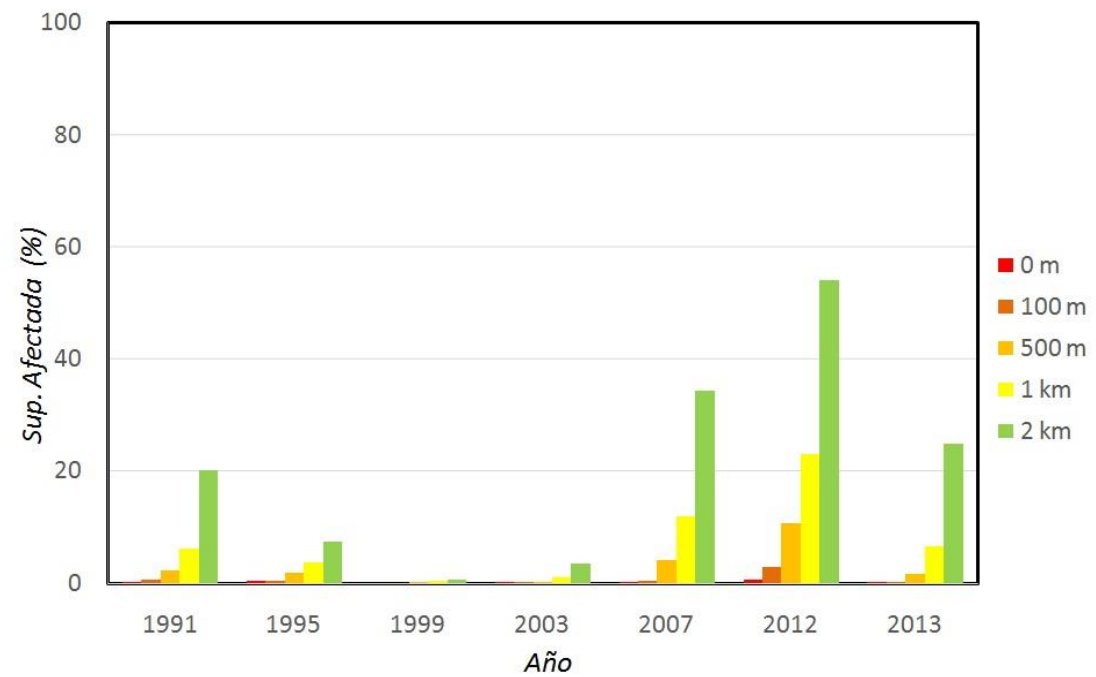

Fuente: Elaboración propia a partir de datos obtenidos de Red de Información Ambiental de Andalucía (REDIAM)

FIGURA 9

Distribución espacial de las áreas de influencia de los siniestros por fuego en las áreas urbanizadas durante el periodo 1991- 2013

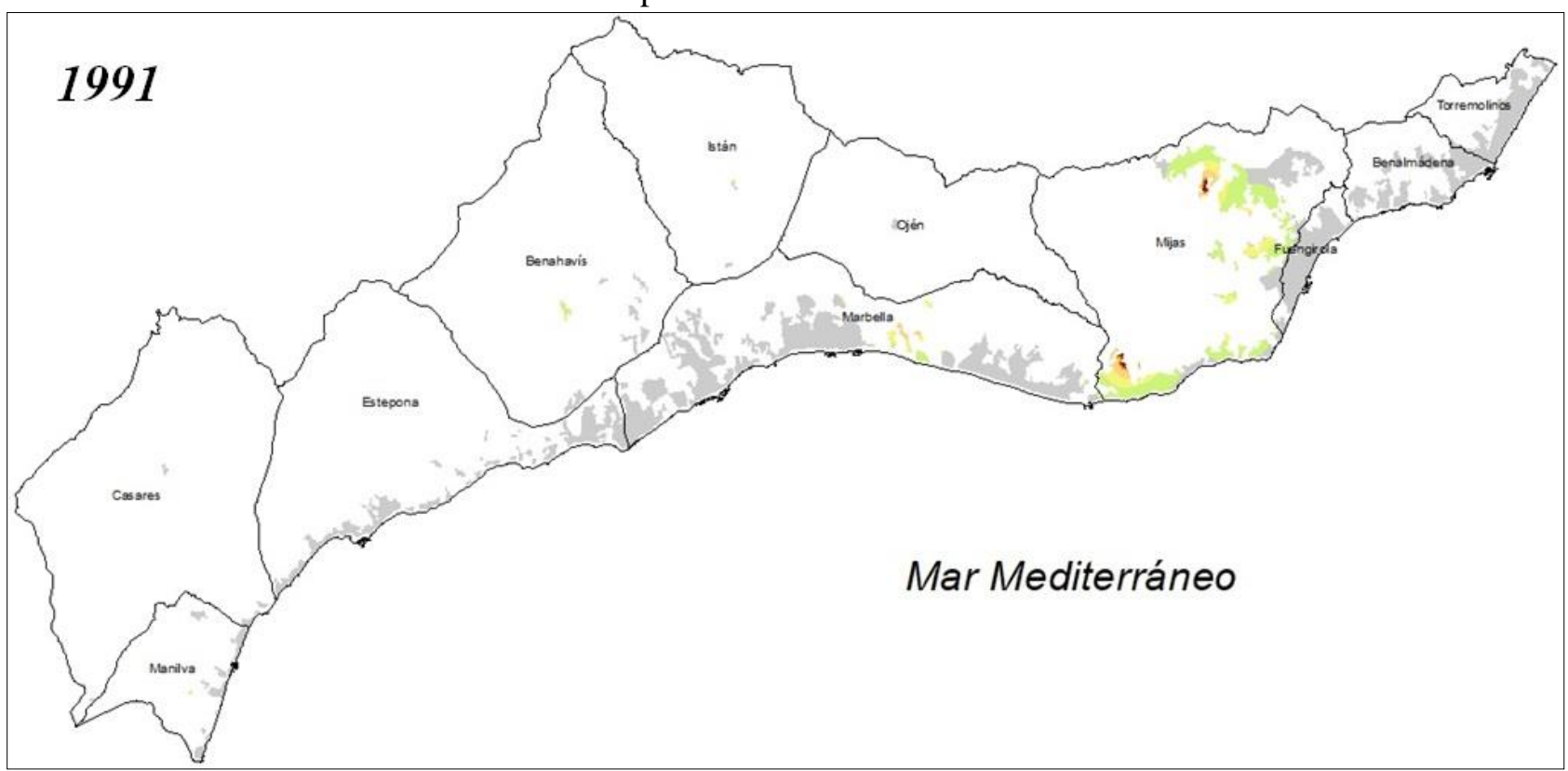



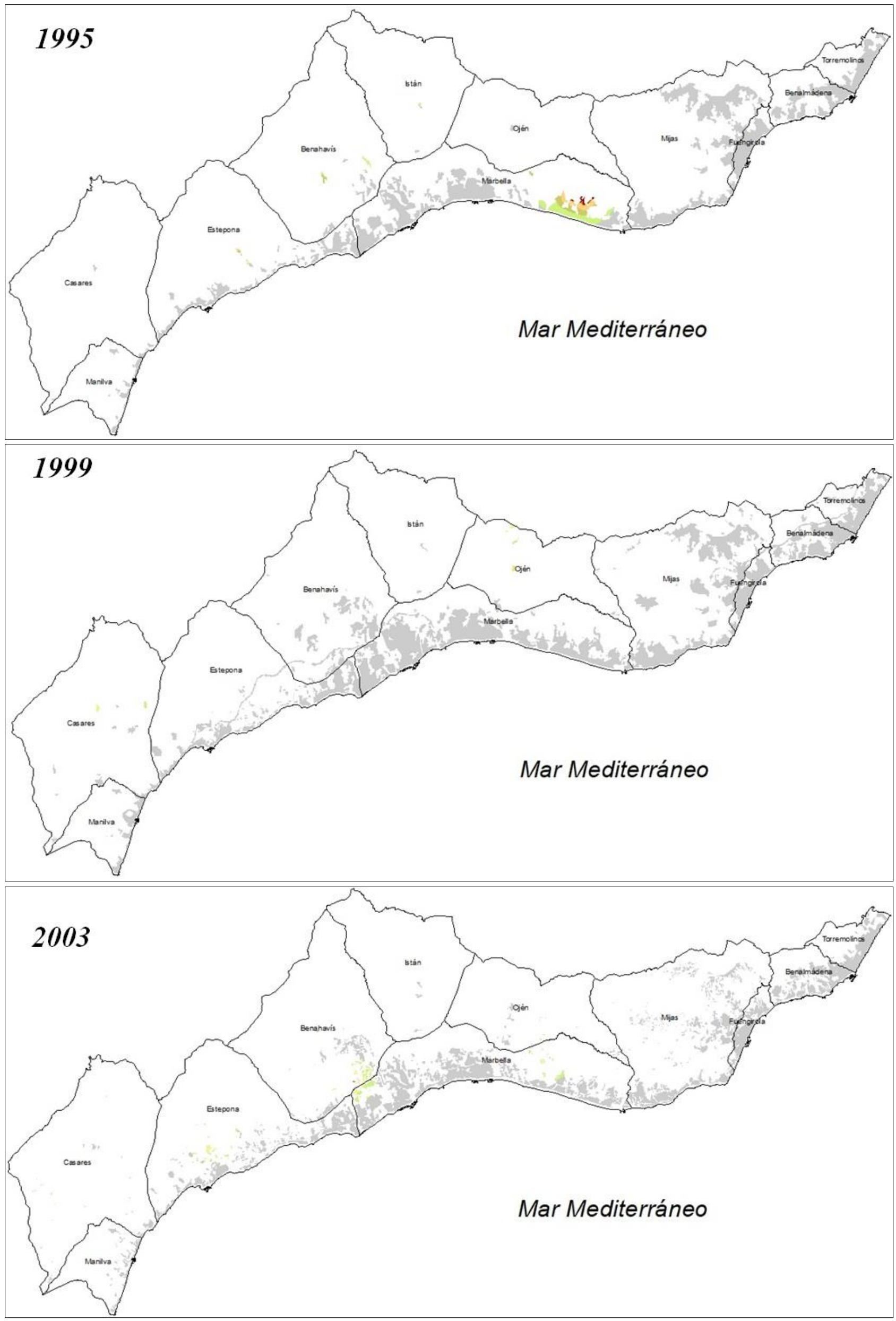

Papeles de Geografía, 65 (2019), 49-66 


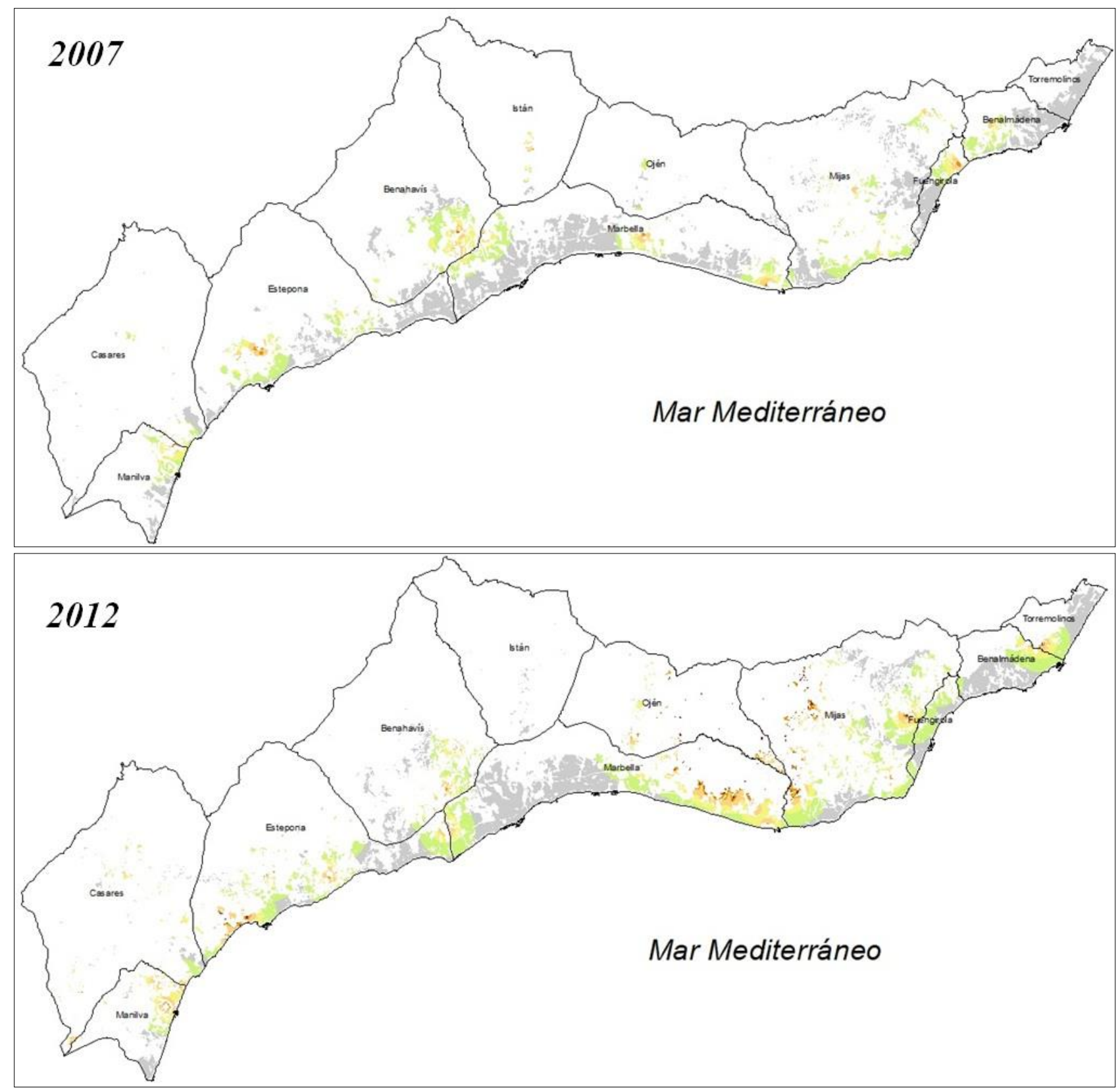




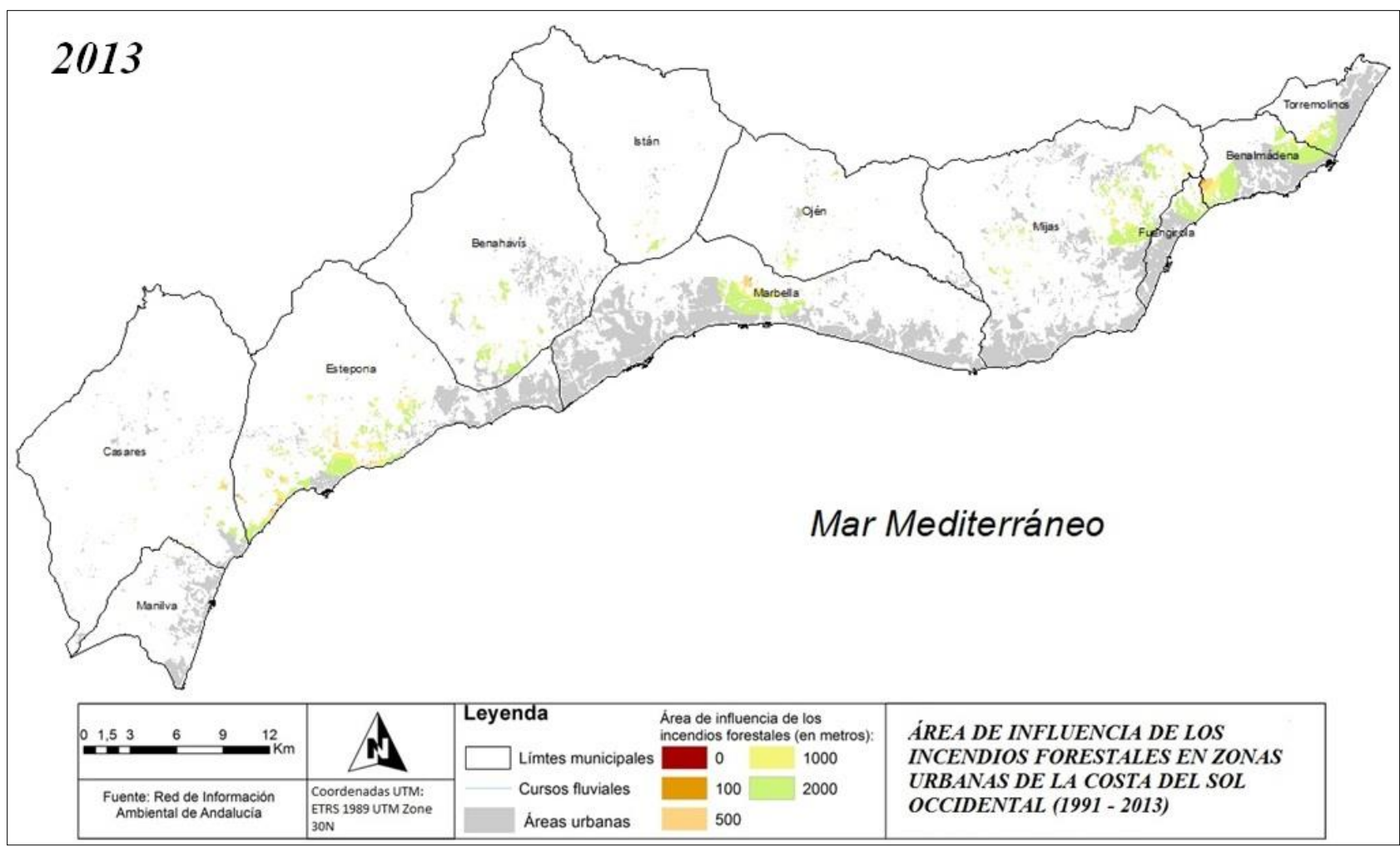

Fuente: Elaboración propia a partir de datos obtenidos de Red de Información Ambiental de Andalucía (REDIAM)

\section{CONCLUSIONES}

Este estudio ha realizado un análisis territorial de los incendios forestales en el periodo 1991-2013 en la Costa del Sol occidental y su afección sobre las áreas urbanizadas, a partir de procedimientos cartográficos. En este periodo, la comarca de la Costa del Sol occidental se sitúo junto a regiones españolas de similares características (economía basada en el turismo y crecimiento desmedido de la superficie urbanizada) entre las más afectadas por el fuego. El crecimiento de las áreas urbanizadas, pasando de apenas un 10\% en 1991 a casi un $20 \%$ de su territorio en 2013, ha hecho que la exposición al riesgo de incendios por parte de la población aumentara en el periodo de estudio, especialmente, en aquellos siniestros que derivan en incendios forestales de gran tamaño. En definitiva, este estudio pone de relieve la gravedad del problema derivado de los incendios forestales, generalmente originados por negligencias y con una mayor frecuencia de ocurrencia en la segunda mitad el periodo analizado, ante el crecimiento de las áreas urbanizadas del ámbito costero mediterráneo español y, en concreto, de la Costa del Sol occidental, siendo espacios que suponen un reto para la gestión territorial.

\section{REFERENCIAS BIBLIOGRÁFICAS}

BADIA, A., SAURÍ, D., CERDÁN, R. y LLURDÉS, J.C. (2002): “Causality and management of forest fires in Mediterranean environments: an example from Catalonia". Environmental Hazards, no 4 (2002), pp. 23 32.

CASTILLO SOTO, M.E. (2012): "The identification and assessment of areas at risk of forest fire using fuzzy methodology". Applied Geography, pp 35, 199-207.

DERA. https://www.juntadeandalucia.es/institutodeestadisticaycartografia/DERA/index.htm [consulta: 25 de Octubre de 2016]

GALACHO JIMÉNEZ, F.B., LUQUE GIL, A. (2000): "La dinámica del paisaje de la Costa del Sol desde la aparición del turismo". Baetica. Estudios de Arte, Geografía e Historia, pp 22, 25-58.

GALIANA MARTÍN, L. (2012): "Las interfaces urbano-forestales: un nuevo territorio de riesgo en España". Boletín de la Asociación de Geógrafos Españoles, pp 58, 205-226. 
GÓMEZ ZOTANO, J., CASTILLO RODRÍGUEZ, J.A, NAVARRO JURADO, E., REYES CORREDERA, S. (2017): "Itinerario por la Costa del Sol Occidental y Serranía de Ronda". Servicio de Publicaciones de la Universidad de Málaga, 260 p. En prensa.

LEIN, J.K. y STUMP, N.I. (2009): “Assessing wildfire potential within the wildland-urban interface:

A southeastern Ohio example". Applied Geography, pp 29, 21-34.

MAPAMA. https://www.mapama.gob.es/ [consulta: 26 de Octubre de 2016]

MONTIEL, C. y HERRERO, G. (2010): “Overview of policies and practices related to fire ignitions". En Sande, J. et al. (eds.): Towards Integrated Fire Management-Outcomes of the European Project Fire Paradox, European Forest Institute, pp. 35-46.

MONTIEL MOLINA, C. (2003): "El turismo de interior en el desarrollo socioeconómico de las comarcas forestales de la Comunidad Valenciana". Investigaciones geográficas, ${ }^{\circ} 31$, pp. 15-36

PYNE, S. J., ANDREW, P.L.y LAVEN, R.D. (1996): “Introduction to Wildland fire”. New York, Wiley, 769 págs.

REDIAM. http://www.juntadeandalucia.es/medioambiente/site/rediam [consulta: 26 de Octubre de 2016]

RODRÍGUEZ BALLESTEROS, C. (2012): "Olas de Calor y de Frío en España desde 1975". Servicio de Banco Nacional de Datos Climatológicos (AEMET), pp. 280-300

ROMERO-CALCERRADA, R., NOVILLO, C.J., MILLINGTON, J.D., GOMEZ-JIMENEZ, I. (2008): “GIS analysis of spatial patterns of human-caused wildfire ignition risk in the SW of Madrid (Central Spain)". Landscape Ecology, pp 23, 341-354.

ROMERO MARTÍNEZ, J.M., ROMERO PADILLA, Y., NAVARRO JURADO, E. (2015): “Atributos urbanos contemporáneos del litoral mediterráneo en la crisis global: caso de la zona metropolitana de la Costa del Sol". Scripta Nova p 515.

VILAR DEL HOYO, L., MARTÍN ISABEL, M.P. y MARTÍNEZ VEGA, J. (2008): "Empleo de técnicas de regresión logística para la obtención de modelos de riesgo humano de incendio forestal a escala regional". Boletín de la Asociación de Geógrafos Españoles, nº 47, pp. 5-29. 